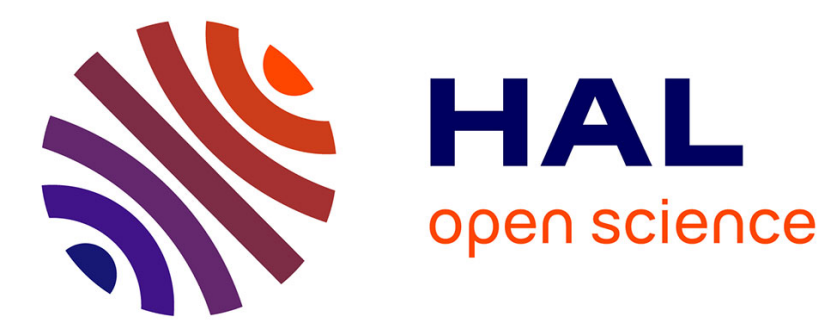

\title{
Iron(III)-induced photooxidation of arsenite in the presence of carboxylic acids and phenols as model compounds of natural organic matter
}

\author{
Xingyun Huang, Ying Peng, Jing Xu, Feng Wu, Gilles Mailhot
}

\section{To cite this version:}

Xingyun Huang, Ying Peng, Jing Xu, Feng Wu, Gilles Mailhot. Iron(III)-induced photooxidation of arsenite in the presence of carboxylic acids and phenols as model compounds of natural organic matter. Chemosphere, 2021, 263, pp.128142. 10.1016/j.chemosphere.2020.128142 . hal-03052429

\author{
HAL Id: hal-03052429 \\ https://hal.uca.fr/hal-03052429
}

Submitted on 10 Dec 2020

HAL is a multi-disciplinary open access archive for the deposit and dissemination of scientific research documents, whether they are published or not. The documents may come from teaching and research institutions in France or abroad, or from public or private research centers.
L'archive ouverte pluridisciplinaire HAL, est destinée au dépôt et à la diffusion de documents scientifiques de niveau recherche, publiés ou non, émanant des établissements d'enseignement et de recherche français ou étrangers, des laboratoires publics ou privés.

\section{(c)(1)}

Distributed under a Creative Commons Attribution| 4.0 International License 


\section{Iron(III)-induced photooxidation of arsenite in the}

2 presence of carboxylic acids and phenols as model

3 compounds of natural organic matter

4

\section{*Corresponding author}

E-mail address: jingxu0506@whu.edu.cn (J. Xu), gilles.mailhot@uca.fr (G. Mailhot).

1 School of Resources and Environmental Science, Wuhan University, Wuhan, 430079, P. R. China

${ }^{2}$ Hubei Academy of Environmental Science, Wuhan, 430072, P. R. China

${ }^{3}$ School of Water Resources and Hydropower Engineering, Wuhan University, Wuhan, 430079, P. R. China

${ }^{4}$ Université Clermont Auvergne, CNRS, SIGMA Clermont, Institut de Chimie de Clermont-Ferrand, F-63000 Clermont-Ferrand, France. 


\section{Abstract}

Iron species have essential influence on the environmental/geochemical behaviors of arsenic species in water and soil. Colloidal ferric hydroxide (CFH) induces photooxidation of arsenite (As(III)) to arsenate $(\mathrm{As}(\mathrm{V}))$ in water at neutral $\mathrm{pH}$ through surface complexation and ligand-to-metal charge transfer (LMCT). However, the effect of the co-existing natural organic matter (NOM) on the complexation-photolysis in this process has remained unclear. In the present work, the photooxidation of $\mathrm{As}(\mathrm{III})$ induced by $\mathrm{CFH}$ was investigated in the presence of various carboxylic acids and polyphenols as simple model compounds of NOM. Two different light sources of ultraviolet A (UVA) $\left(\lambda_{\max }=365 \mathrm{~nm}\right)$ and ultraviolet B (UVB) $\left(\lambda_{\max }=313 \mathrm{~nm}\right)$ were used for photooxidation treatment of the experimental ternary system and the control binary system respectively. The obtained results demonstrated that all investigated NOM inhibited the photooxidation of As(III) in the As(III)/CFH system at $\mathrm{pH}$ 7. Moreover, the correlation analysis between the pseudo-first order rate constant $k_{\mathrm{obs}}$ and various property parameters of NOM showed that the stable constant for the complexation between $\mathrm{Fe}(\mathrm{III})$ and $\mathrm{NOM}\left(\log \mathrm{K}_{\mathrm{Fe}-\mathrm{NOM}}\right)$ as well as the molecular weight of NOM and the percentages of total acidity of NOM exhibited significant correlations. A simple quantitative structure-activity relationship (QSAR) model was established between $k_{\mathrm{obs}}$ and these three parameters utilizing a multiple linear regression method, which can be employed to estimate the photooxidation efficiency of As(III) in the presence of ferric iron and NOM. Thus, the present work contributes to the understanding of the environmental interactions between NOM and iron.

\section{Keywords:}

Arsenic, Iron, Natural organic matter, Photochemical oxidation, Quantitative structure-activity relationship model 


\section{Introduction}

Arsenic is a toxic substance exhibiting carcinogenic properties. Hence, the pollution of the environment with this element has become the cause for concern (Smedley and Kinniburgh, 2002; Hughes, 2002; Ball, 2005). In natural aqueous environments, arsenic primarily exists in inorganic oxyacid forms, including arsenite (As(III)) and arsenate (As(V)) (Cullen and Reimer, 1989). It is widely known that As(III) is more mobile and displays higher toxicity than $\mathrm{As}(\mathrm{V})$. Thus, the process of oxidative conversion of the former to $\mathrm{As}(\mathrm{V})$ is of significance.

The adsorption and oxidation of various metals and their oxides, particularly ones of iron, aluminium, and manganese, affect the form and migration of arsenic in the environment (Oscarson et al., 1981). Our previous study investigated the photochemical oxidation of $\mathrm{As}(\mathrm{III})$ on nascent colloidal ferric hydroxide $(\mathrm{CFH})$ in aqueous solutions at $\mathrm{pH}$, revealing the mechanism of the transformation of As(III) to $\operatorname{As}(\mathrm{V})$. The conducted analysis demonstrated that the photochemical oxidation of As(III) in the presence of nascent $\mathrm{CFH}$ occurred through an electron transfer from As(III) to $\mathrm{Fe}$ (III), induced by absorption of radiation into the ligand-to-metal charge-transfer (LMCT) band (Xu et al., 2014). Nonetheless, to date, the environmental photochemical processes of the iron-arsenic complexes have not been extensively investigated. This is a consequence of insufficient research into the influence of NOM prevalent in natural waters on the iron-arsenic interaction as well as on the photochemical oxidation processes.

In natural waters, NOM is a mixture of substances formed through the breakdown 
of plant and animal tissues by biological and chemical processes (Ma et al., 2001). It has been demonstrated that the main functional groups of the NOM components include carboxylic, carbonyl, phenol, and catechol moieties. Evidence also suggests that both As(V) and As(III) can bind to NOM (Thanabalasingam and Pickering, 1986; Liu and Cai, 2010). Notably, the complexation of arsenic with NOM plays an important role in regulating the mobility and transformation of this element in the aquatic environment (Buschmann et al., 2006). Furthermore, interactions with natural organic acids are known to modify the stability and surface reactivity of iron hydroxides (Cheng et al., 2019). Consequently, in view of the high concentrations of iron in natural systems in comparison to those of trace metals, competitive binding of iron to NOM may affect the binding, and thus the fate of other metals.

However, as NOM possesses various active functional groups and exhibits large molecular weight, studies involving these substances are often problematic. In many cases, model compounds, such as low molecular weight aliphatic acids, have been employed to simulate the behaviors and/or mechanisms of NOM (Yost et al., 1990; Boily and Fein, 2000; Giannakopoulos et al., 2005). Some of these acids serve as metabolic intermediates in the citric acid and glyoxylate cycles of plants. Examples of such compounds include citric, succinic, fumaric, and malic acids. In addition to the acids, which are continuously being recycled in plants by different metabolic processes, other low molecular weight acids, such as the end products of metabolic pathways of plants, are also known. Examples of these include lactic and oxalic (Wershaw, 2019). And Fe(III)-oxalate is a representative model Fe(III) complex and often used in the study of iron complexes (Zuo, 1995; Chen et al., 2013). Moreover, gallic acid is produced in plants by a degradation reaction and contains a number of hydroxyl $(-\mathrm{OH})$ moieties. Recent investigations demonstrated that at $\mathrm{pH} \sim 8$ (natural seawater $\mathrm{pH}$ ), the compound is deprotonated, which results in the formation of 
anionic ligands capable of complexing to metals, as the organic ligands at the cell surface of microorganisms (González et al., 2014; López et al., 2015; Santana-Casiano et al., 2010). Polyphenols were included in the present study, because compounds containing hydroxyl and carboxyl functionalities have been shown to complex to Fe(III) (González et al., 2019). The catechol is an organic functional compound. It can form stable complexes with various divalent and trivalent metal ions, among which trivalent ion complexes are the most stable. Depending on the $\mathrm{pH}$ value, many mono-, di-, or tri-coordinated complexes can be formed. Among them, the monocoordinated complexes are formed preferentially in a higher proportion. Fe(III) can react with catechol to form a complex to produce $\mathrm{Fe}(\mathrm{II})$ and semiquinone radicals. This is a $\mathrm{pH}$-dependent process, which is related to changes in the $\mathrm{Fe}(\mathrm{III}) / \mathrm{Fe}$ (II) redox potential and effective composite stability (Santana-Casiano et al., 2014). Catechol and iron complexes also prevent metals from undergoing redox reactions, as in the case of dicoordinated iron(III) complexes. In contrast, monocoordination complexes allow iron to participate in the electron transfer reaction. This experiment mainly assumes that the ligand form is mainly a single ligand for simulation calculation (Santana-Casiano et al., 2010). NOM possessing carboxylic acids and/or polyphenols is suspected to affect the photooxidation of As(III) on the surface of $\mathrm{CFH}$. However, the structure-activity relationship between these model compounds of NOM and their influence on the photochemical reactivity of the As(III)-CFH complexes remain ambiguous. Buschmann et al.(2005)reported Suwannee River humic acid as the typical dissolved natural organic matter (DOM) induced As(III) photooxidation under UV-A and visible light from a medium-pressure mercury lamp. For $5 \mathrm{mg} \mathrm{L}^{-1}$ of dissolved organic carbon (DOC) and $60 \mathrm{~mW} \mathrm{~cm}{ }^{-2}$ UV-A irradiation $(366 \mathrm{~nm})$, the rate coefficient $\mathrm{k}_{\exp }$ was $1.27 \times 10^{-2} \mathrm{~min}^{-1}(250$ $\mathrm{nM} / 100 \mathrm{~min}$ initial rate was ca. $5.08 \times 10^{-3} \mu \mathrm{M} \mathrm{min}^{-1}$ ). Such rate is negligible in our system. And they also fail to study the transformation mechanism of As(III) from the interaction of arsenic, iron and NOM. In fact, in addition to the adsorption of inorganic arsenic on the surface of iron (hydrogen) oxide forms an internal phase 
complex between surface functional groups and arsenic. Arsenic and iron can also complex with humus substance. Furthermore, interactions with natural organic acids are known to modify the stability and surface reactivity of iron hydroxides. Moreover, in view of the high concentration of iron in natural systems, compared to those of trace metals, competitive binding of iron onto HS may affect the binding, and then the fate, of other metals.

Thus, in the present study, we investigated the effect of NOM on the photochemical oxidation process of $\mathrm{As}(\mathrm{III})$ in a $\mathrm{As}(\mathrm{III}) / \mathrm{CFH}$ system. Eleven widely-known compounds containing at least two active functional groups (bicarboxylic acids, hydroxyl carboxylic acids, hydroxyl aromatic carboxylic acids, polycarboxylic acids, and polyphenols) were employed as the model compounds of NOM in the environment. A simple quantitative structure-activity relationship (QSAR) model was used to determine the correlation between the properties of NOM and the observed rate constant $\left(k_{o b s}\right)$. Additionally, the principal structure/property parameters, which impacted the activity of NOM, influencing the photolysis of As(III)-CFH, were determined. Considering that the photochemical processes may differ with the irradiation wavelength, UVA $\left(\lambda_{\max }=365 \mathrm{~nm}\right)$ and UVB $\left(\lambda_{\max }=313 \mathrm{~nm}\right)$ lamps were utilized as light sources. The present study contributes to the understanding of the sunlight-driven geochemical cycle as well as the fate of arsenic in environments containing NOM and iron.

\section{Materials and methods}

\subsection{Chemicals}

Sodium arsenite $\mathrm{NaAsO}_{2}$ (99.5\%) was obtained from Xiya Reagent Center (Chengdu, China) and was used after $24 \mathrm{~h}$ of drying in a desiccator. Sodium arsenate $\mathrm{Na}_{2} \mathrm{HAsO}_{4} \cdot 7 \mathrm{H}_{2} \mathrm{O}(98 \%)$ was provided by Alfa Aesar Chemical Co., Ltd. (Tianjin, China). $\mathrm{Fe}_{2}\left(\mathrm{SO}_{4}\right)_{3}$ (analytical reagent (AR) grade) was purchased from Guangdong 
Taishan Chemical Co., Ltd. and was employed as the iron source. Cis-butenedioic acid (AR), lactic acid (AR), butanedioic acid (AR), ethanedioic acid dihydrate (AR), citric acid monohydrate (AR), salicylic acid (AR), ethylenediaminetetraacetic acid (AR), $\mathrm{NaOH}(\mathrm{AR}), \mathrm{H}_{2} \mathrm{SO}_{4}(\mathrm{AR}), \mathrm{HCl}(\mathrm{AR}), \mathrm{KOH}(\mathrm{AR}), \mathrm{NaH}_{2} \mathrm{PO}_{4} \cdot 2 \mathrm{H}_{2} \mathrm{O}$ (AR), and $\mathrm{Na}_{2} \mathrm{HPO}_{4} \cdot 12 \mathrm{H}_{2} \mathrm{O}(\mathrm{AR})$ were purchased from Sinopharm Chemical Reagent Co., Ltd. (Shanghai, China). L-(-)-Malic acid (98\%), gallic acid (99\%), 4-nitrocatechol(>98.0\%), and catechol $(99.0 \%)$ were provided by Aladdin Industrial Corporation (Shanghai, China). 1,4-Piperazinediethanesulfonic acid (PIPES, 99.5\%) was obtained from Aladdin Biochemical Technology Co., Ltd. (Shanghai, China). $\mathrm{KBH}_{4}(\geq 97.0 \%)$ was purchased from Shanghai Lingfeng Chemical Reagent Co., Ltd. The property parameters of model compounds of NOM used in this study are listed in Table S1 (Supplementary material). Gallic acid and catechol (configured with cooled boiling water) were reconfigured upon each use. All solutions were prepared using deionized water with resistivity of $18.2 \mathrm{M} \Omega \mathrm{cm}$ obtained from a water purification system (Youpu Ultra Pure Technology Co., Ltd., Sichuan, China). All of the prepared solutions were stored at $4{ }^{\circ} \mathrm{C}$ and protected from light.

\subsection{Photochemical reaction}

The emission spectra of the UVA or UVB lamps as the light sources used in the photoreaction experiment, and the schematic of the photoreactor are illustrated in Fig. S1a and $1 \mathrm{~b}$ (Supplementary material), respectively. The emission spectra ranges were 340-400 nm and 290-360 nm with wavelengths of $365 \mathrm{~nm}$ and $311 \mathrm{~nm}$, correspondingly. The intensities of the emitted light were $5.5 \mathrm{~mW} \mathrm{~cm}^{-2}$ and $11.8 \mathrm{~mW}$ 
$\mathrm{cm}^{-2}$, for UVA and UVB lamps respectively (measure the intensity of light after passing through the reactor wall and circulating water layer inside the reactor). As illustrated in Fig. S1b, the center of the protective sleeve consisted of a cylindrical plexiglass water-jacketed reactor with cooling circulation. A magnetic stirrer was placed under the reactor. Around the reactor, a quadrilateral light source cover was installed, which involved a symmetrical number of UVA lamps on each side of the inner wall. Moreover, ten UVA or UVB lamps ( $8 \mathrm{~W}$ ) used for irradiation were placed symmetrically around the reactor.

The reaction solutions containing Fe(III), As(III), PIPES, and NOM, as well as ones without NOM, were transferred into a $500 \mathrm{~mL}$ reactor. The reaction temperature was set to $25^{\circ} \mathrm{C}$ and maintained using a circulating water unit. The piperazine- $N, N^{\prime}$-bis(2-ethanesulfonic acid) (PIPES) buffer was utilized to maintain the $\mathrm{pH}$ at $7.0 \pm 0.1$. Subsequently, the lamps were switched on and the extent of the As(III) oxidation was evaluated by collecting $4.5 \mathrm{~mL}$ samples at fixed interval times. The samples were quenched with $0.5 \mathrm{~mL}$ of $1: 1(\mathrm{v} / \mathrm{v}) \mathrm{HCl} /$ water prior to conducting the tests. All experiments were conducted on solutions that had been exposed to the atmosphere. It is noteworthy that all experiments were repeated 2-3 times, and the variations between experiments are shown by error bars.

\subsection{Analysis}

The reactions were analyzed by liquid chromatography-hydride generation-atomic fluorescence spectrometry (LC-HG-AFS; Bohui Instrument Co., Ltd., Beijing, China) using a $5 \% \mathrm{HCl}-2 \% \mathrm{KBH}_{4}$ solution. Argon $(99.99 \%)$ was used as a carrier and 
shielding gas during the analysis. The concentrations of As(III) and As(V) were determined and the observed rate of As(III) oxidation $\left(k_{o b s}\right)$ was calculated based on the pseudo-first order kinetics using equation (1). The time period of 0-20 min was selected for the calculation of $k_{o b s}$. The $k_{o b s}$ value was set as the activity parameter, with which the simple linear fitting and multivariate correlation analyses were conducted to obtain the chemical property parameters of NOM. The correlation analysis was performed by employing the Origin 9.0 software. The values of $k_{\mathrm{obs}}$ established under UVA and UVB irradiation were denoted as $k_{o b s-U V A}$ and $k_{o b s-U V B}$, respectively.

$$
-\ln \left(C / C_{0}\right)=k_{o b s} \times t \#(1)
$$

where $t$ is the reaction time, $C_{0}$ and $C$ are the initial concentration of As (III) and the concentration at any time $t$ in the reaction, and $k_{o b s}$ is the initial apparent rate constant of the quasi first-order equation. The ultraviolet-visible (UV-Vis) absorption spectra of the solutions containing $\mathrm{Fe}(\mathrm{III})$-As(III) mixtures were recorded in a $1 \mathrm{~cm}$ quartz cuvette using a Shimadzu UV-1601 spectrophotometer (Kyoto, Japan).

\section{Results and discussion}

3.1. Photochemical oxidation of $\mathrm{As}$ (III) in the presence of $\mathrm{Fe}$ (III) and various NOM

The results of As(III) photooxidation in systems containing various NOM as well as in the control systems (As(III) alone and Fe(III) + As(III) without NOM) under UVA and UVB irradiation are shown in Fig. 1 and 2. Moreover, the experimental values of 
$k_{o b s-U V A}$ and $k_{o b s-U V B}$ are listed in Table $\mathrm{S} 2$. The $\mathrm{pH}$ was set to $\mathrm{pH} 7$ for all investigated systems, as it is an average $\mathrm{pH}$ of natural waters and the efficiency of photochemical

221 oxidation of $\mathrm{As}(\mathrm{III})$ induced by $\mathrm{CFH}$ at $\mathrm{pH} 7$ was high. As shown in Fig. 1 and 2, the 222 observed rate constants $k_{\text {obs-UVA }}$ and $k_{\text {obs-UVB }}$ for $5 \mu \mathrm{M} \mathrm{As}(\mathrm{III})$ in the presence of $66 \mu \mathrm{M}$ $223 \mathrm{Fe}(\mathrm{III})$ were determined at $0.045 \mathrm{~min}^{-1}$ and $0.127 \mathrm{~min}^{-1}$, respectively. The two $k_{\mathrm{obs}}$ 224 values were used as the corresponding baselines to evaluate the effects of NOM in 225 photochemical systems under UVA and UVB irradiation, respectively. Moreover, the 226 curves for the control system, abbreviated as Fe + As, are presented in all panels in 227 Fig. 1 and 2. It was established that compared with the fast As(III) photooxidation in the presence of $\mathrm{CFH}$, no reaction occurred in the absence of $\mathrm{Fe}(\mathrm{III})$ under UVA or 229 UVB irradiation. This outcome is in accordance with our previous report (Xu et al., 2014). 


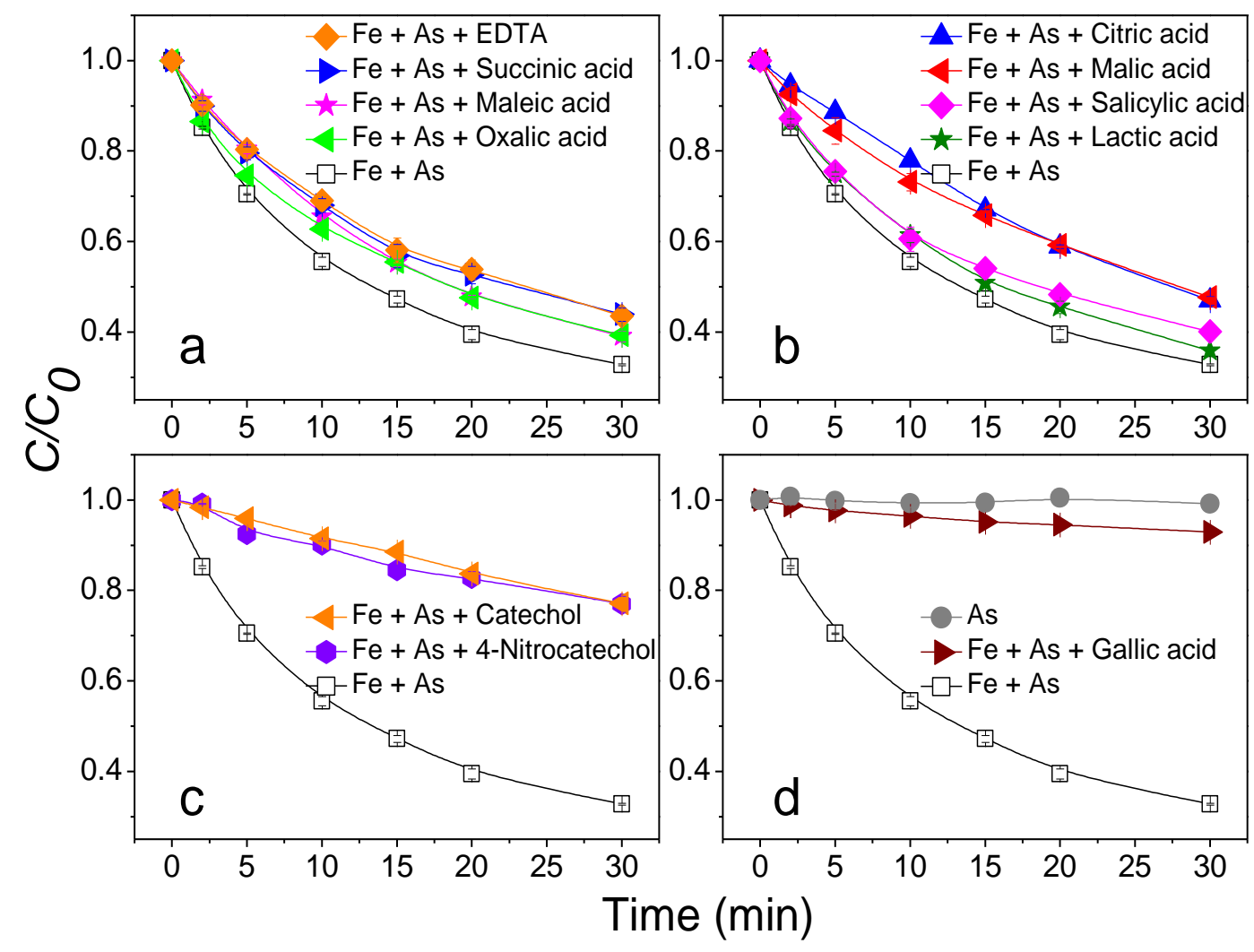

233 Fig. 1. Effects of different NOM on the photooxidation of As(III) in the presence of Fe(III) under

234 UVA light source. Initial conditions: $[\mathrm{Fe}(\mathrm{III})]=66 \mu \mathrm{M},[\mathrm{As}(\mathrm{III})]=5 \mu \mathrm{M},[\mathrm{NOM}]=10 \mu \mathrm{M}$,

$$
[\mathrm{PIPES}]=5 \mathrm{mM}, \mathrm{pH}=7 .
$$

Fig. 1 and 2 show that the addition of $10 \mu \mathrm{M}$ of each NOM under UVA and UVB irradiation inhibited the oxidation of As(III) to varying degrees. The main reason for this observation is thought to be competitive complexation(Catrouillet et al., 2016). NOM exhibit stronger complexing ability than the As(III) oxyanion; therefore, the investigated compounds inhibited the photochemical oxidation of As(III) via the $\mathrm{Fe}(\mathrm{III})-\mathrm{As}(\mathrm{III})$ complex. In this case, NOM prevented the surface complexation of the As(III) oxyanion onto CFH at neutral $\mathrm{pH}$ and cut-off the pathway of LMCT. It has previously been shown that in ternary systems with metals, e.g. NOM and adsorbent (mineral), NOM can bind directly on the oxide surface, causing blockage of the sites and reduction of the adsorption efficiency (Lai et al., 2002; Fakour et al., 2016). Wang et al. (2013) reported that As(III) was not measurably oxidized in the presence of 
excess EDTA (i.e. Fe(II):EDTA < 1:1), contrasting with the rapid oxidation of Fe(II) by $\mathrm{O}_{2}$ and $\mathrm{H}_{2} \mathrm{O}_{2}$ at neutral $\mathrm{pH}$ under the same conditions. However, partial oxidation of As(III) was observed at a 2:1 ratio of Fe(II):EDTA. Rapid Fe(II) oxidation in the presence of organic ligands did not necessarily result in the coupled As(III) oxidation. As such, formation of reactive oxidants via iron-catalyzed reactions drives As(III) oxidation and organic ligands regulate the extent and rate of As(III) oxidation by manipulating iron speciation, nature and concentrations of Fenton oxidants. In this study, it is proposed that EDTA competes with As(III) to coordinate with $\mathrm{Fe}(\mathrm{III})$, and the formation of $\mathrm{Fe}(\mathrm{III})-\mathrm{As}(\mathrm{III})$ complexes is gradually reduced in this process, which can also indicate that excessive EDTA completely inhibits oxidation of As(III) under neutral conditions. Consequently, the complexing functional groups in NOM are the predominant features affecting the oxidation rate of As(III).

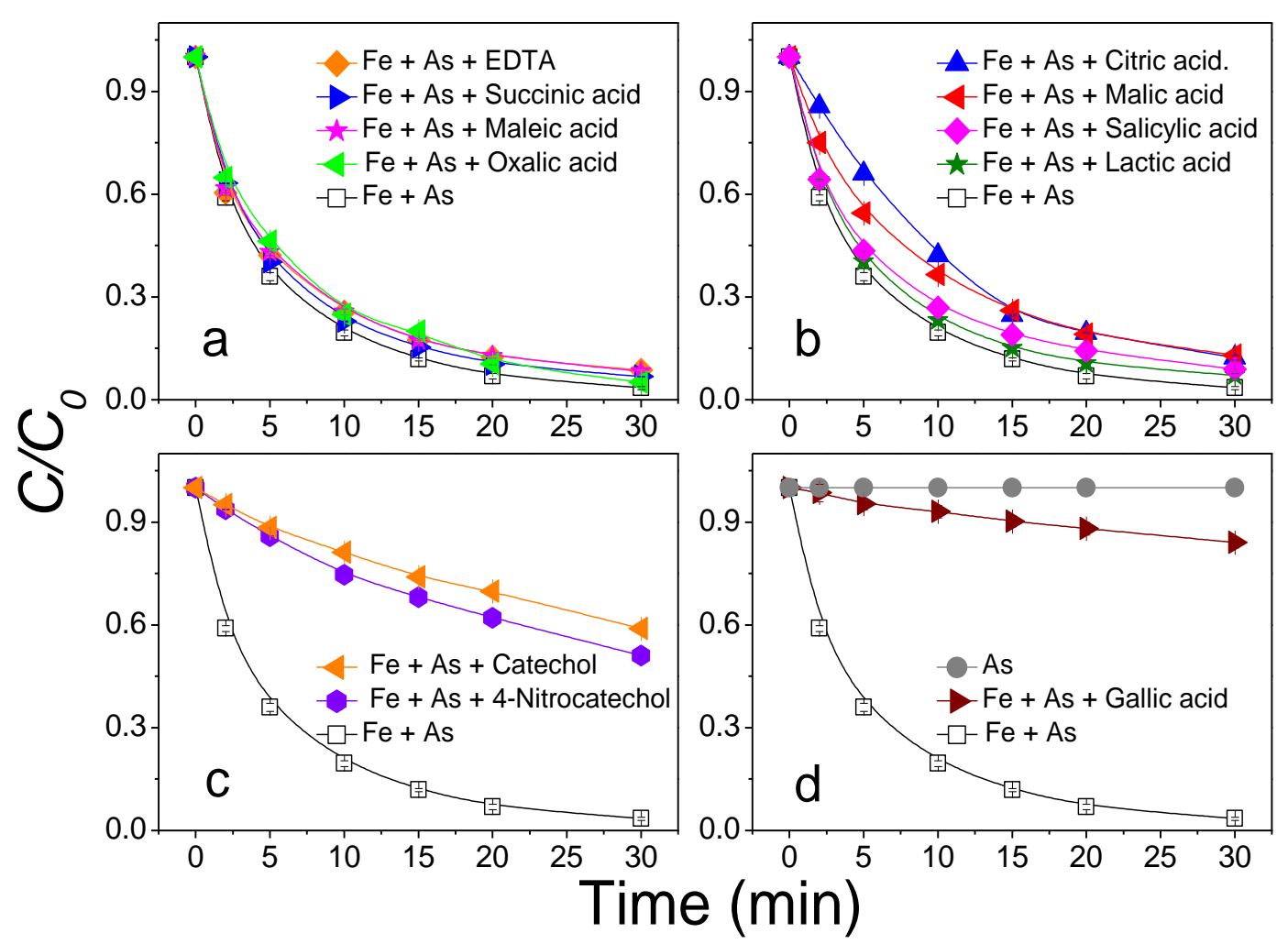

Fig. 2. Effects of different NOM on the photooxidation of As(III) in the presence of Fe(III) under 
Based on the data presented in Fig. 1 and Table S2, the values of $k_{\mathrm{obs}-U V A}$ in the presence of various NOM were determined and classified into three groups. The first group (group I), with $k_{\text {obs-UVA }}$ of $0.026-0.039 \mathrm{~min}^{-1}$ (relative standard deviation, RSD $15 \%$ ), included lactic, maleic, salicylic, oxalic, succinic, citric, and malic acids as well as EDTA (Figs. 1a and 1b). Moreover, the second group (group II) with $k_{\mathrm{obs}-U V A}$ established at $0.0087-0.0099 \mathrm{~min}^{-1}(\mathrm{RSD} 9 \%)$ included 4-nitrocatechol and catechol (Fig. 1c). Lastly, the third group (group III), with a $k_{\mathrm{obs}-U V A}$ value of $0.0028 \mathrm{~min}^{-1}$, involved gallic acid (Fig. 1d). The relative minimum inter-group variances of $k_{\mathrm{obs}-U V A}$ between each group were determined at $62 \%$ (between group I and II) and $68 \%$ various NOM were also classified into three groups. The value of $k_{\mathrm{obs}-U V B}$ for the first group was determined at $0.081-0.109 \mathrm{~min}^{-1}$ (Fig. 2a and 2b, RSD 10\%), while for the

UVA and UVB irradiation.

Overall, the classification in terms of $k_{o b s}$ correlates with the present functional groups. Group I includes polycarboxylic acids (Figs. 1a and 2a) or hydroxyl 
carboxylic acids (Fig. 1b and 2b), group II contains polyphenols without carboxyl moieties (Fig. 1c and 2c), while group III consists of carboxylic polyphenols (Fig. 1d and 2d). However, such classification is not sufficiently precise, particularly for NOM in group I. For instance, polycarboxylic acids and hydroxyl carboxylic acids exhibit similar $k_{o b s}$ values; however, the order of these carboxylic acids in terms of $k_{o b s}$ is mixed and dissimilar under UVA and UVB irradiation. It was not possible to classify the compounds in group I into two subgroups according to the number of hydroxyl and carboxyl functionalities. Additionally, salicylic acid is an aromatic carboxylic acid, but it is more similar to other carboxylic acids rather than to polyphenols or gallic acid. This implies that the mono-aromatic ring is not a significant structural property of the investigated NOM.

\subsection{Effects of the wavelength bands of the light sources}

The $k_{o b s-U V B}$ value is noticeably larger than the corresponding $k_{o b s-U V A}$ value for each evaluated NOM. Analogous results were obtained for the system without NOM, where the ratio of $k_{o b s-U V B} / k_{o b s-U V A}$ was established at 2.82 . The quantum yields of the photolysis of the $\mathrm{Fe}(\mathrm{III})-\mathrm{As}(\mathrm{III})$ complex were estimated to be close $\left(\emptyset_{U V B} / \emptyset_{U V A}=1.4\right.$, Text S1 and Fig. S2). Hence, the difference between $k_{o b s-U V B}$ and $k_{o b s-U V A}$ in the absence of NOM can be attributed to the intensity of the radiation and its absorption by the Fe(III)-As(III) complex, which is not wavelength-dependent. Additionally, to confirm whether the effect of the NOM structure on $k_{o b s}$ is dependent on the wavelength, the correlation analysis between $k_{o b s-U V A}$ and $k_{o b s-U V B}$ in the presence of 
NOM was carried out, as shown in Fig. 3. Linear fitting analysis demonstrated that both in the presence and in the absence of NOM, $k_{o b s-U V B}$ was approximately three

311 times higher than $k_{o b s-U V A}$, and the correlation was significant $(\mathrm{r}=0.996, \mathrm{p}<0.001)$. This result confirmed the hypothesis that the effect of NOM at low concentrations is not dependent on the wavelength band of UVB and UVA, but on the structure.

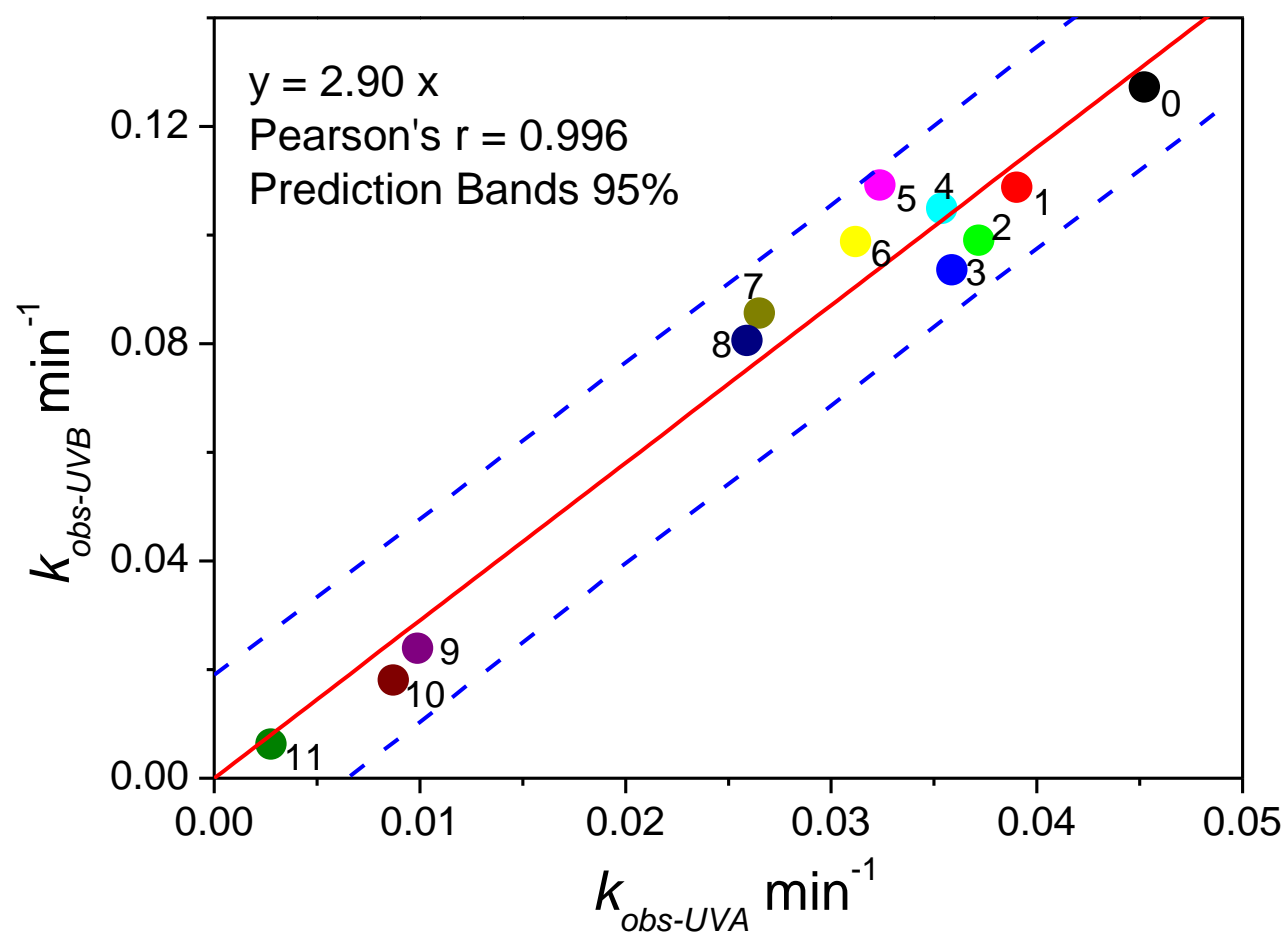

Fig. 3. Comparative analysis of $k_{o b s}$ under UVA and UVB light sources in the presence and absence of NOM. The number 0 represents $k_{o b s}$ without NOM, and 1-11 represent $k_{o b s}$ with various NOM (1: lactic acid, 2: maleic acid, 3: salicylic acid, 4: oxalic acid, 5: succinic acid, 6: EDTA, 7: citric acid, 8: malic acid, 9: 4-nitrocatechol, 10: catechol, and 11: gallic acid).

\subsection{Relationship between the property parameters of NOM and $\boldsymbol{k}_{o b s}$}

The relationships between $k_{o b s}$ and various NOM property parameters were examined to determine the key properties of NOM, which inhibit the oxidation of As(III) in the 
presence of $\mathrm{CFH}$. The chemical composition properties of the NOM investigated in this study were simply linearly fitted with the values of $k_{\text {obs }}$. The results of the Pearson's correlation carried out to examine the relationships between the variables are shown in Table 1. No significant correlation was observed between $k_{o b s}$ and the elemental composition of $\mathrm{NOM}(\mathrm{C} \%, \mathrm{H} \%$, or $\mathrm{O} \%, \mathrm{p}>0.05)$. Notably, the parameters of the molecular weight, number of functional groups, acidic functional groups, and pKa (the negative logarithm of the overall acidity constant for the overall ionization reaction of the polyprotic acid) exhibited significant correlation ( $\mathrm{p}<0.05$ or 0.01 ). Most importantly, the correlations between $k_{\text {obs-UVA }}$ or $k_{\text {obs-UVB }}$ and $\log \mathrm{K}_{\mathrm{Fe}-\mathrm{NOM}}$ or $\mathrm{pKa} \mathrm{a}_{1}$ (the negative logarithm of the acidity constants for the first stage in which a polyprotic acid loses a proton) of NOM were exceptionally significant $(\mathrm{p}<0.001)$ and the linear fit curves are presented in Fig. S3. The value of $k_{o b s}$ displayed a significant negative correlation with $\log \mathrm{K}_{\mathrm{Fe}-\mathrm{NOM}}$, which confirmed that NOM inhibited the oxidation of $\mathrm{As}(\mathrm{III})$ by destroying the $\mathrm{Fe}(\mathrm{III})$-As(III) complexes. Therefore, the number/type of functional groups as well as the ionization constant of NOM, which was related to its complexing properties, also exhibited comparatively significant correlation with $k_{o b s}$. Because EDTA and salicylic acid may also form bidentate or tridentate coordination with $\mathrm{CFH}$ using the adjacent aromatic carboxyl or phenolic hydroxyl moieties, the values of $\log \mathrm{K}_{\mathrm{Fe}-\mathrm{Sal}}$ and $\log \mathrm{K}_{\mathrm{Fe}-\mathrm{EDTA}}$ were divided by 2 and 3 prior to the correlation analysis, respectively (Fujii et al., 2014). Such treatment of the obtained data resulted in a more significant correlation. 
Table 1

351 Correlation coefficients between $k_{o b s}$ with the property parameters of NOM $(* * * \mathrm{p}<0.001$, **p $<$ $0.01,{ }^{*} \mathrm{p}<0.05$ and $\mathrm{p}=$ Pearson correlation coefficient).

\begin{tabular}{|c|c|c|c|c|c|c|}
\hline \multirow[t]{2}{*}{$k_{o b s}$} & \multirow{2}{*}{$\begin{array}{c}\text { Molecular } \\
\text { weight }\end{array}$} & \multicolumn{3}{|c|}{ elemental composition (\%) } & \multicolumn{2}{|c|}{$\begin{array}{l}\text { Number of functional } \\
\text { groups }\end{array}$} \\
\hline & & $\mathrm{C}$ & $\mathrm{H}$ & $\mathrm{O}$ & $\mathrm{N}_{\mathrm{COOH}}$ & $\mathrm{N}_{\mathrm{OH} \text { or } \mathrm{NH} 2}$ \\
\hline$k_{o b s-U V A}$ & $-0.647^{*}$ & -0.445 & 0.185 & 0.466 & 0.501 & $-0.805 * *$ \\
\hline \multirow[t]{3}{*}{$k_{o b s-U V B}$} & $-0.672 *$ & -0.542 & 0.202 & 0.544 & $0.617 *$ & $-0.806 * *$ \\
\hline & \multicolumn{3}{|c|}{ acidic functional groups (\%) } & & & \\
\hline & Carboxyl & Hydroxyl & $\begin{array}{c}\text { total } \\
\text { acidity }\end{array}$ & $\log \mathrm{K}_{\mathrm{Fe}-\mathrm{NOM}}$ & $\mathrm{pKa}_{1}$ & $\mathrm{pKa}$ \\
\hline$k_{o b s-U V A}$ & $0.731^{*}$ & $-0.786 * *$ & $0.623^{*}$ & $-0.967 * * *$ & $-0.894 * * *$ & $-0.606^{*}$ \\
\hline$k_{o b s-U V B}$ & $0.807 * *$ & $-0.848 * * *$ & $0.698^{*}$ & $-0.954 * * *$ & $-0.905 * * *$ & $-0.672 *$ \\
\hline
\end{tabular}

Prior to the multi-element correlation analysis in terms of QSAR, the correlation analysis between each property of NOM listed in Table S3 was performed to ensure that the multivariate analysis does not include any autocorrelation factors in the same equations. The results presented in Table S3 show that molecular weight (Mw), Total acidity $\%, \mathrm{~N}_{\mathrm{COOH}}, \mathrm{N}_{\mathrm{OH}}, \log \mathrm{K}_{\mathrm{Fe}-\mathrm{NOM}}$, and $\mathrm{pKa}$ exhibit a significant auto-correlation with at least two other parameters among all the nine parameters linearly correlated with 
acidity $\%$, and $\log \mathrm{K}_{\mathrm{Fe}-\mathrm{NOM}}$, do not show any correlation between each other. Thus, the two parameter and three parameter multiple linear regressions were performed within the six and three parameters, respectively. The results presented in Table 2 indicate that the three-parameter regressions fit the data better than the two parameter regressions under UVA or UVB irradiation. Thus a simple QSAR model of $k_{o b s}$ is established with molecular weight, total acidity $\%$ and $\log \mathrm{K}_{\mathrm{Fe}-\mathrm{NOM}}$ concerning the effect of NOM on As(III) photooxidation. The comparison between the experimental and calculated values of $k_{o b s}$ utilizing the developed QSAR model is shown in Fig. 4. The solid line represents the fitted curve, while the dotted line marks the 95\% confidence prediction interval. As it can be seen, under UVA or UVB irradiation, the correlation coefficients, $\mathrm{R}^{2}$, of the fitted QSAR model were 0.929 and 0.914 , respectively, and all the data were within the $95 \%$ prediction interval. It is noteworthy that the $\log \mathrm{K}_{\mathrm{Fe}-\mathrm{NOM}}$ parameter accounted for a large proportion in the fitting formula. This meant that among the chemical properties of NOM, the most important factor affecting $k_{o b s}$ was the coordination equilibrium constant between NOM and iron. In addition, some of the two-parameter regressions were also significant, e.g., molecular weight and $\mathrm{pKa}_{1}$. Thus, these simpler models may also be utilized to estimate $k_{o b s}$ when $\log \mathrm{K}_{\mathrm{Fe}-\mathrm{NOM}}$ data are not available (Fig. S4). 
Table 2

390 Ternary linear fitting of $k_{o b s}(\mathrm{UVA}$ and UVB) with property parameters of all NOM evaluated in

$391 \quad$ this study

\begin{tabular}{|c|c|c|c|c|c|}
\hline & No. & Linear Fitting Equation & $\begin{array}{c}\text { Adj. } \\
\text { R-Square }\end{array}$ & $\begin{array}{l}\text { Residual } \\
\text { Sum of } \\
\text { Squares }\end{array}$ & $\begin{array}{c}\mathrm{F} \\
\text { Value }\end{array}$ \\
\hline \multirow{16}{*}{$\operatorname{Binary}(1)$} & (1) & $k_{\text {obs }-U V A}=0.0527-0.0000554 \mathrm{Mw}-0.00432 \mathrm{pKa}_{1}$ & $0.827 * * *$ & 2.28E-04 & 24.9 \\
\hline & (2) & $k_{\text {obs-UVA }}=0.0318+0.00321 \mathrm{~N}_{\mathrm{COOH}}-0.00943 \mathrm{~N}_{\mathrm{OH} \text { or NH} 2}$ & $0.665 * *$ & 4.41E-04 & 10.9 \\
\hline & (3) & $k_{\text {obs }-U V A}=0.0304+0.0000715 \mathrm{Mw}-0.01126 \mathrm{~N}_{\mathrm{OH} \text { or } \mathrm{NH} 2}$ & $0.659 * *$ & 4.50E-04 & 10.6 \\
\hline & (4) & $k_{\text {obs }-U V A}=0.0462-0.0000632 \mathrm{Mw}-0.000897 \mathrm{OH} \%$ & $0.622 * *$ & 4.99E-04 & 9.21 \\
\hline & $(5)$ & $k_{\text {obs }-U V A}=0.0151-0.0000256 \mathrm{Mw}+0.000285 \mathrm{COOH} \%$ & $0.435^{*}$ & 7.44E-04 & 4.85 \\
\hline & (6) & $k_{\text {obs }-U V A}=0.0372+0.00386 \mathrm{~N}_{\mathrm{COOH}}-0.00121 \mathrm{pKa}$ & $0.441 *$ & $7.36 \mathrm{E}-04$ & 4.95 \\
\hline & (7) & $k_{\text {obs-UVA }}=0.0422+0.0000563 \mathrm{Mw}-0.00168 \mathrm{pKa}$ & 0.346 & $8.62 \mathrm{E}-04$ & 3.64 \\
\hline & (8) & $k_{o b s-U V A}=0.00636-0.0000131 \mathrm{Mw}+0.000338$ Tot acid $\%$ & 0.239 & $1.00 \mathrm{E}-03$ & 2.57 \\
\hline & (9) & $k_{o b s-U V B}=0.149-0.000112 \mathrm{Mw}-0.0133 \mathrm{pKa}_{1}$ & $0.808 * * *$ & 2.37E-03 & 22.0 \\
\hline & $(10)$ & $k_{o b s-U V B}=0.0851+0.0139 \mathrm{~N}_{\mathrm{COOH}}-0.0275 \mathrm{~N}_{\mathrm{OH} \text { or NH} 2}$ & $0.772 * * *$ & $2.82 \mathrm{E}-03$ & 17.9 \\
\hline & $(11)$ & $k_{o b s-U V B}=0.0805+0.000296 \mathrm{Mw}-0.0409 \mathrm{~N}_{\mathrm{OH} \text { or NH} 2}$ & $0.742 * *$ & $3.19 \mathrm{E}-03$ & 15.3 \\
\hline & $(12)$ & $k_{o b s-U V B}=0.132-0.000141 \mathrm{Mw}-0.00291 \mathrm{OH} \%$ & $0.701 * *$ & $3.69 \mathrm{E}-03$ & 12.7 \\
\hline & (13) & $k_{\text {obs }-U V B}=0.103+0.0157 \mathrm{~N}_{\mathrm{COOH}}-0.00362 \mathrm{pKa}$ & $0.587 * *$ & $5.10 \mathrm{E}-03$ & 8.10 \\
\hline & (14) & $k_{\text {obs }-U V B}=0.0283-0.0000175 \mathrm{Mw}+0.000970 \mathrm{COOH} \%$ & $0.566^{*}$ & $5.36 \mathrm{E}-03$ & 7.51 \\
\hline & (15) & $k_{\text {obs }-U V B}=0.120+0.000260 \mathrm{Mw}-0.00569 \mathrm{pKa}$ & $0.449 *$ & $6.79 \mathrm{E}-03$ & 5.08 \\
\hline & (16) & $k_{o b s-U V B}=-0.00399+0.0000275 \mathrm{Mw}+0.00119$ Total acidity $\%$ & 0.361 & $7.88 \mathrm{E}-03$ & 3.82 \\
\hline \multirow{6}{*}{ Binary(2) } & (17) & $k_{\text {obs-UVA }}=0.0568-0.0000246 \mathrm{Mw}-0.00237 \log \mathrm{K}_{\mathrm{Fe}-\mathrm{NOM}}$ & $0.935 * * *$ & $8.63 \mathrm{E}-05$ & 72.4 \\
\hline & (18) & $k_{o b s-U V A}=0.0491+0.0000458$ Tot acid $\%-0.00226 \log \mathrm{K}_{\mathrm{Fe}-\mathrm{NOM}}$ & $0.925 * * *$ & $9.91 \mathrm{E}-05$ & 62.5 \\
\hline & (19) & $k_{\text {obs-UVA }}=0.0550-0.000540 \mathrm{~N}_{\mathrm{COOH}}-0.00245 \log \mathrm{K}_{\mathrm{Fe}-\mathrm{NOM}}$ & $0.921 * * *$ & $1.04 \mathrm{E}-04$ & 59.6 \\
\hline & (20) & $k_{o b s-U V B}=0.125+0.000353$ Total acidity $\%-0.00627 \log \mathrm{K}_{\mathrm{Fe}-\mathrm{NOM}}$ & $0.925 * * *$ & $9.30 \mathrm{E}-04$ & 62.3 \\
\hline & $(21)$ & $k_{o b s-U V B}=0.145+0.0041 \mathrm{~N}_{\mathrm{COOH}}-0.00667 \log \mathrm{K}_{\mathrm{Fe}-\mathrm{NOM}}$ & $0.902 * * *$ & $1.20 \mathrm{E}-03$ & 47.3 \\
\hline & (22) & $k_{o b s-U V B}=0.161-0.0000176 \mathrm{Mw}-0.00719 \log \mathrm{K}_{\mathrm{Fe}-\mathrm{NOM}}$ & $0.890 * * *$ & $1.36 \mathrm{E}-03$ & 41.3 \\
\hline Ternary & (23) & $k_{\text {obs }-U V A}=0.0551-0.0000432 \mathrm{Mw}+0.00139 \mathrm{~N}_{\mathrm{COOH}}-0.00218$ & $0.932 * * *$ & 7.85E-05 & 46.6 \\
\hline
\end{tabular}




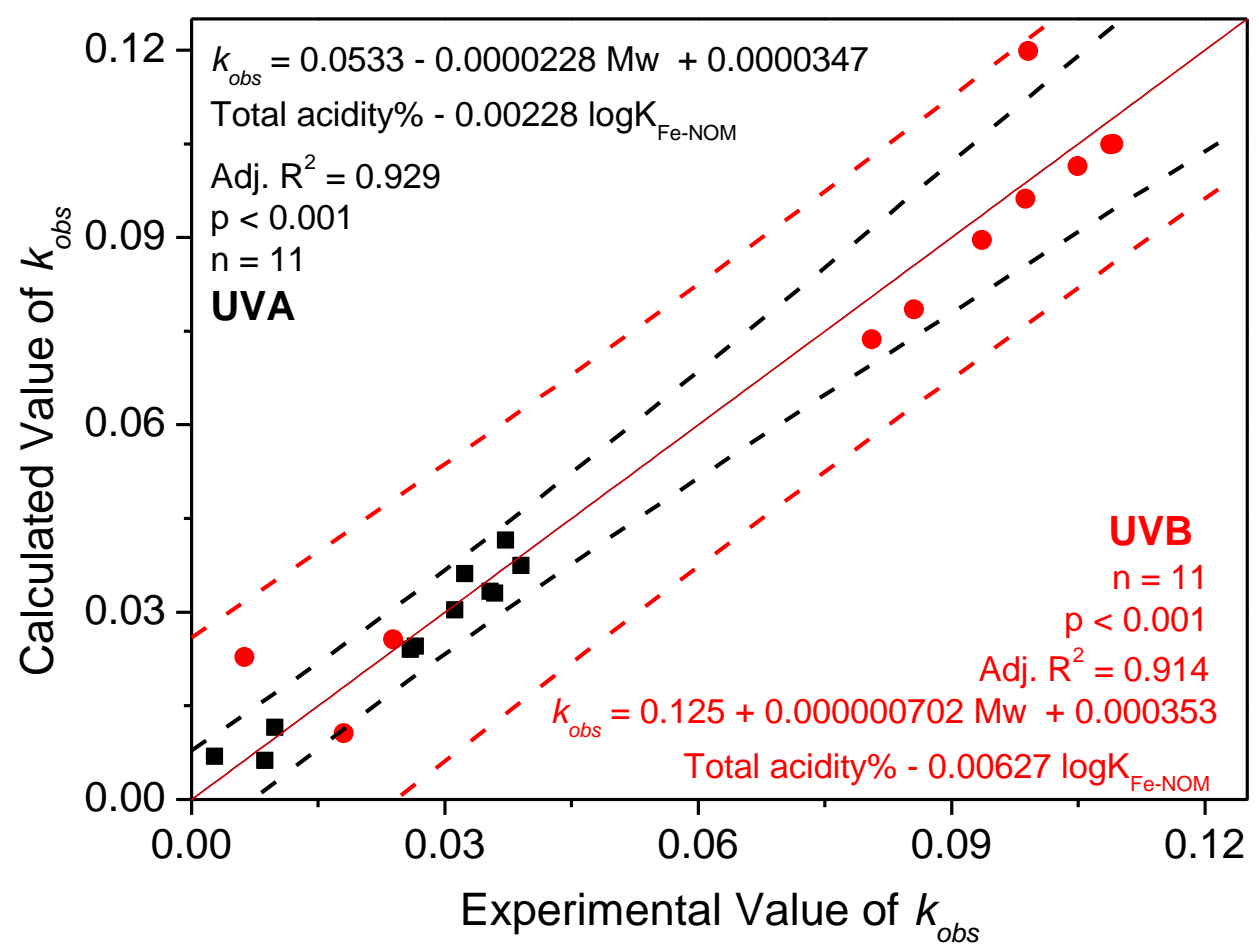

Fig. 4. Comparison of the experimental and theoretical $k_{o b s}$ values.

\section{Conclusion}

Employing a panel of various carboxylic acids and polyphenols as the model compounds for NOM, we established that $10 \mu \mathrm{M}$ of $\mathrm{NOM}$ inhibited the photooxidation efficiency of $\mathrm{As}(\mathrm{III})$ in the presence of ferric iron in the form of

400 colloidal ferric hydroxide in water at circumneutral $\mathrm{pH}$. This inhibition effect was 401 attributed to the competitive complexation with Fe(III) by NOM vs. As(III), i.e., 402 NOM competes with As(III) to reduce the formation of the Fe(III)-As(III) complex, thereby reducing the rate of the ligand to metal electron transfer during the photolysis and subsequent oxidation of As(III). The described effects were structure-dependent, 
and the predominant property parameters affecting the process were in the order of $\log \mathrm{K}_{\mathrm{Fe}-\mathrm{NOM}}>$ molecular weight $>$ total acidity $\%$. Notably, a simple QSAR equation using these three parameters as the variables was employed to estimate the influence of other NOM not included in this investigation. The present work provides for the first time a valuable reference to understanding the impact of NOM on the interactions between arsenic and iron (hydr)oxides as well as to extending the existing knowledge on the environmental processes of iron species in water. It highlights the important role that organic matter can play on environmental processes and therefore the paramount importance of taking NOM into account in natural processes.

\section{ACKNOWLEDGEMENTS}

This work was financially supported by the National Natural Science Foundation of China (No. 21777125), the Opening Fund of the State Key Laboratory of Environmental Geochemistry (SKLEG2019720).

\section{References}

Ball, P., 2005. Arsenic-free water still a pipedream. Nature 436, 313. https://doi.org/10.1038/436313a.

Boily, J.F., Fein, J.B., 2000. Proton binding to humic acids and sorption of $\mathrm{Pb}(\mathrm{II})$ and humic acid to the corundum surface. Chem. Geol. 168, 239-253. https://doi.org/10.1016/S0009-2541(00)00197-2.

Buschmann, J., Canonica, S., Lindauer, U., Hug, S.J., Sigg, L., 2005. Photoirradiation of dissolved 
humic acid induces arsenic(III) oxidation. Environ. Sci. Technol. 39, 9541-9546 https://doi.org/10.1021/es051597r.

Buschmann, J., Kappeler, A., Lindauer, U., Kistler, D., Berg, M., Sigg, L., 2006. Arsenite and arsenate binding to dissolved humic acids: Influence of $\mathrm{pH}$, type of humic acid, and aluminum. Environ. Sci. Technol. 40, 6015-6020. https://doi.org/10.1021/es061057+.

Catrouillet, C., Davranche, M., Dia, A., Bouhnik-Le Coz, M., Demangeat, E., Gruau, G., 2016. Does As(III) interact with $\mathrm{Fe}(\mathrm{II}), \mathrm{Fe}(\mathrm{III})$ and organic matter through ternary complexes? J. Colloid Interface Sci. 470, 153-161. https://doi.org/10.1016/j.jcis.2016.02.047.

Chen, Y., Zhang, K., Zuo, Y., 2013. Direct and indirect photodegradation of estriol in the presence of humic acid, nitrate and iron complexes in water solutions. Sci. Total Environ. 463-464, 802-809. https://doi.org/10.1016/j.scitotenv.2013.06.026.

Cheng, W., Hanna, K., Boily, J.F., 2019. Water Vapor Binding on Organic Matter-Coated Minerals. Environ. Sci. Technol. 53, 1252-1257. https://doi.org/10.1021/acs.est.8b05134.

Cullen W, Reimer K, 1989. Arsenic Speciation in the Environment. Chem. Rev. 89(4), 713-764. https://doi.org/10.1021/cr00094a002.

Fakour, H., Lin, T.F., Lo, S.L., 2016. Equilibrium Modeling of Arsenic Adsorption in a Ternary Arsenic-Iron Oxide-Natural Organic Matter System. Clean - Soil, Air, Water 44, 1287-1295. https://doi.org/10.1002/clen.201500962.

Fujii, M., Imaoka, A., Yoshimura, C., Waite, T.D., 2014. Effects of molecular composition of natural organic matter on ferric iron complexation at circumneutral pH. Environ. Sci. Technol. 48, 4414-4424. https://doi.org/10.1021/es405496b.

Giannakopoulos, E., Christoforidis, K.C., Tsipis, A., Jerzykiewicz, M., Deligiannakis, Y., 2005. 
González, A.G., Cadena-Aizaga, M.I., Sarthou, G., González-Dávila, M., Santana-Casiano, J.M., 2019. https://doi.org/10.1016/j.chemgeo.2018.10.017.

González, A.G., Pokrovsky, O.S., Jiménez-Villacorta, F., Shirokova, L.S., Santana-Casiano, J.M.,

González-Dávila, M., Emnova, E.E., 2014. Iron adsorption onto soil and aquatic bacteria: XAS structural study. Chem. Geol. 372, 32-45. https://doi.org/10.1016/j.chemgeo.2014.02.013.

Hughes, M.F., 2002. Arsenic toxicity and potential mechanisms of action. Toxicol. Lett. 133, 1-16. https://doi.org/10.1016/s0378-4274(02)00084-X.

Lai, C.H., Chen, C.Y., Wei, B.L., Yeh, S.H., 2002. Cadmium adsorption on goethite-coated sand in the presence of humic acid. Water Res. 36, 4943-4950. https://doi.org/10.1016/S0043-1354(02)00009-X.

Liu, G., Cai, Y., 2010. Complexation of arsenite with dissolved organic matter: Conditional distribution coefficients and apparent stability constants. Chemosphere 81(7), 890-896. https://doi.org/10.1016/j.chemosphere.

López, A., Rico, M., Santana-Casiano, J.M., González, A.G., González-Dávila, M., 2015. Phenolic profile of Dunaliella tertiolecta growing under high levels of copper and iron. Environ. Sci. Pollut. 22, 14820-14828. https://doi.org/10.1007/s11356-015-4717-y.

Ma, H., O’Loughlin, E.J., Burris, D.R., 2001. Factors affecting humic-nickel complex mediated reduction of trichloroethene in homogeneous aqueous solution. Environ. Sci. Technol. 35(4), 717-724. https://doi.org/10.1021/es001314p. 
Oscarson, D.W., Huang, P.M., Defosse, C., Herbillon, A., 1981. Oxidative power of Mn(IV) and Fe(III) oxides with respect to As(III) in terrestrial and aquatic environments. Nature 291(5810), 50-51. https://doi.org/10.1038/291050a0.

Santana-Casiano, J.M., González-Dávila, M., González, A.G., Millero, F.J., 2010. Fe(III) reduction in the presence of Catechol in seawater. Aquat. Geochemistry 16, 467-482. https://doi.org/10.1007/s10498-009-9088-x.

Santana-Casiano, J.M., González-Dávila, M., González, A.G., Rico, M., López, A., Martel, A., 2014. Characterization of phenolic exudates from Phaeodactylum tricornutum and their effects on the chemistry of $\quad \mathrm{Fe}(\mathrm{II})-\mathrm{Fe}(\mathrm{III}) . \quad$ Mar. $\quad$ Chem. 158, 10-16. https://doi.org/10.1016/j.marchem.2013.11.001.

Smedley, P.L., Kinniburgh, D.G., 2002. A review of the source, behaviour and distribution of arsenic in natural waters. Appl. Geochem. 17, 517-568. https://doi.org/10.1016/S0883-2927(02)00018-5.

Thanabalasingam, P., Pickering, W.F., 1986. Arsenic Sportion by Humic Acids. Environ. Pollut. Ser. B, Chem. Phys. 12, 233-246. https://doi.org/http://dx.doi.org/10.1016/0143-148X(86)90012-1.

Wang, Z., Bush, R.T., Liu, J., 2013. Arsenic(III) and iron(II) co-oxidation by oxygen and hydrogen peroxide: Divergent reactions in the presence of organic ligands. Chemosphere 93, 1936-1941. https://doi.org/10.1016/j.chemosphere.2013.06.076.

Wershaw, B.R.L., 2019. Evaluation of Conceptual Models of Natural Organic Matter ( Humus ) From a Consideration of the Chemical and Biochemical Processes of Humification. 1-58. https://pubs.usgs.gov/sir/2004/5121/.

Xu, J., Li, J., Wu, F., Zhang, Y., 2014. Rapid Photooxidation of As(III) through Surface Complexation with Nascent Colloidal Ferric Hydroxide. Environ. Sci. Technol. 48, 272-278. 
494 Yost, E.C., Tejedor-tejedor, M.I., Anderson, M.A., 1990. In situ CIR-FTIR characterization of salicylate complexes at the goethite/aqueous solution interface. Environ. Sci. Technol. 24, 0-6. https://doi.org/10.1021/es00076a005.

Zuo, Y., 1995. Kinetics of photochemical/chemical cycling of iron coupled with organic substances in 